\title{
Victimisation of Married Pakistani Women from Three Types of Aggression Perpetrated by their Mother-in-Law, and Mental Health Concomitants
}

\author{
Taalia Khan, Karin Österman, Kaj Björkqvist \\ Åbo Akademi University, Finland \\ taalia.khan@abo.fi, karin.osterman@abo.fi,kaj.bjorkqvist@abo.fi
}

\begin{abstract}
The aim of the study was to investigate victimisation of married women from aggression perpetrated by the mothers-in-law, and its psychological concomitants. A questionnaire was completed by 569 married women in Pakistan. The mean age was 31.4 years (SD 9.1). Mothers-in-law perpetrated more verbal and indirect aggression than physical aggression against their daughters-in-law. Anxiety, depression, obsessive compulsive symptoms, and somatisation were all associated with aggression perpetrated by the mothers-inlaw. The mothers-in-law had significantly more often than the husbands perpetrated indirect aggression against the daughters-in-law, while the husbands had perpetrated both physical and verbal aggression against their wife significantly more often than the mothers-in-laws. It was concluded that aggression perpetrated by mothers-in-law is a significant problem and associated with mental health problems in married Pakistani women.
\end{abstract}

Keywords. physical, verbal, and indirect aggression, mental health, mothers-in-law, Pakistan

\section{Introduction}

\subsection{Family Hierarchy and Generational Roles}

A joint family in South Asia has been defined as more than one generation of a family living together in the same household where the family members succeed one after the other according to a predefined hierarchical structure and take on different roles (Mirza, 2017). In the Indian culture, roles and responsibilities of family members are based largely on multiple social hierarchies with divisions based on gender roles and generational roles (Fernandez, 1997). For a married couple, the young daughter-inlaw's primary relationship is with her mother-in-law, while the son's primary relationship is with his father (Mies, 1980). The cultural inferiority given to a girl child over a male child, the joint family system, and the bonding between the mother and the son are the three sociocultural norms that create a strained relationship between a daughter-in-law and a mother-in-law (Rew, Gangoli, \& Gill, 2013).

\subsection{Daughters as Lesser Creatures}

The Indian view on a woman's position in the family differs greatly from that of the Western world (Fernandez, 1997). Under the religious realm, women in India are dangerous and powerful beings and, 
therefore, they must be strictly controlled, especially their sexuality (ibid.). Daughters are considered inferior in Indian culture and therefore, mothers and sons naturally enjoy a higher status which gives more bargaining and controlling power to a mother-in-law over the daughter-in-law (Rew et al., 2013). Such patriarchal hierarchies in households lead to many psychosocial issues in the life of a married couple (ibid). It has been found, in a Pakistani sample, that daughters-in-law who were more than average victimised from dowry-related aggression had significantly higher scores on anxiety, depression, obsessive compulsive symptoms, and somatisation than daughters-in-law who were less than average victimised from dowry-related aggression (Khan, Österman, \& Björkqvist, 2020). Dowryrelated aggression carried out by the mother-in-law showed even higher predictive power on the same four mental health concomitants - anxiety, depression, obsessive compulsive symptoms, and somatisation - than aggression perpetrated by the husband. Furthermore, somatic symptoms of the daughter-in-law showed the highest association with dowry-related aggression carried out by the mother-in-law (ibid.). Another study has also found that married women suffered from anxiety, depression, low self-esteem, and severe physical and mental exhaustion due to constant overwork at home as well as from gossip and complaints being conveyed to the husband by the mother-in-law (Mirza, 2017).

\subsection{Interference in Married Life}

A common notion in Pakistani society is that men should provide for their family which includes not just their spouse and children but also for their parents and siblings (Ali, O'Cathain, \& Croot, 2018). Therefore, other family members often feel threatened by the entry of a daughter-in-law and fear that the son will not take care of them as he used to, and that he will spend more money on his wife and children (ibid.). The situation is also prone to cause misunderstandings between the husband and wife which may escalate into intimate partner aggression.

A good Indian daughter-in-law must abide by the elders and listen to her mother-in-law in matters of childbearing (Kumar, Burdone, \& Muttarak, 2016). Private discussions between husband and wife are restricted, and the mother-in-law is mostly the one taking decisions on pregnancy (Char, Saavala, \& Kulmala, 2010). A study conducted in India revealed that in rural parts, mothers-in-law did not only influence the childbearing decisions by the daughters-in-law but also the timings of sexual intercourse and the use of contraceptives (ibid.). Socio-economic and demographic factors play a vital role in household decision making in Pakistan. Women in urban areas are more independent, and hence, they more often have an equal say in household decisions including private decisions like childbearing and contraceptive usage (Mahmood, 2002). In a qualitative study in Nepal, it was found that that mothersin-law mostly had a negative effect on daughters'-in-law propensity to seek antenatal care (Simkhada, Porter, \& van Teijlingen, 2010). The main factor was their preoccupation with daughters-in-law fulfilling their household duties and power relations between mothers-in-law and daughters-in-law.

In Pakistan, it has been found that strained relationships between husband and wife do not only exist when living in a joint family system but living distantly from in-laws can still lead to instigation, thus leading to intimate partner aggression (Ali et al., 2018). Mothers-in-law and sisters-in-law have been found to interfere through telephones and electronic media, expressing their concern and complaints about the daughters-in-law and thus causing tensions in husband-wife relationships. Victimisation from both the husband and the mother-in-law simultaneously has been shown to have the highest association with psychological problems in the daughter-in-law (Khan, Österman, \& Björkqvist, 2021). Direct and indirect involvement, clash of generations, religious duty to abide by the elders, insecurity to lose power, the complexity of the relationship between a mother-in-law and a daughter-in-law, and hence oppression, lead to family abuse in the joint family systems in South Asia (Mirza, 2017).

\subsection{Overseas Pakistanis and Brides}

Many Pakistani young girls get married to Pakistani men who are settled abroad. When doing so they enter into the joint family system where they must keep up with the traditions and abide by the husband 
and the in-laws to keep up their family reputation and good upbringing (Ali et al., 2018). Despite living in the US, the cultural values of these families are conservative, and mothers-in-law are still the central figures of the family (Wasim, 2014). Control and power by the in-laws are exerted on the daughters-inlaw by taking advantage of their lack of knowledge about their rights in Western countries (Ali et al., 2018). In a study conducted on South Asian American daughters-in-law, 25\% of the respondents reported emotional abuse inflicted on them by the mother-in-law (Wasim, 2014). The study revealed that mothers-in-law and daughters-in-law had a complicated relationship which impacted the daughterin-law psychologically.

\subsection{The Media and the Joint Family System}

The broadcast media has always been influential in South Asian countries; it projects the joint family system, domestic politics, and the effects these create. In the early 2000's, a turning point came in the television drama industry, that created waves for the South Asian community. Ekta Kapoor, a renowned Indian producer, writer, and director came up with two dramas "Kyunki Saas Bhi Kabhi Bahu Thi" (Because mother-in-law was a daughter-in-law once) and "Kahani Ghar Ghar Ke" (Story of every household) that unfolded the realities of relationships, love and struggles faced in a joint family system primarily by the daughters-in-law. Likewise, in Pakistan, also many television dramas project such issues, and they reach out to millions of South Asian viewers across the globe. "Humsafar" (Life Partner), "Zindagi Gulzar Hai" (Life is beautiful), "Durr-e-Shehwar" (name of the lead character), and "Bilqees Kaur" (name of the lead character) are some of the most popular dramas of the 2000s that drastically depicted the realities and psychological stress on women due to marital issues. The issue is so deep rooted that women find themselves in these fictional characters and take cues from them to find out their true feelings and reactions, which they have been hiding for years in their married life.

\subsection{The Joint Family System and Domestic Aggression}

Abuse perpetrated by mothers-in-law in middle-class Indian households is largely based on the custom of patrilocality according to which the newlywed wife moves in with her in-laws (Rew et al., 2013). This custom automatically gives the mother-in-law a higher hierarchical position, and she starts to exert her control over the daughter-in-law claiming that she loves her son equally much as the wife does (ibid.). The oppression of daughters-in-law by mothers-in-law can be so critical that it leads to serious psychological problems and long-term health issues (Mirza, 2017). Mothers-in-law (and other older women in the family) have even been observed to promote and instigate their sons to abuse their wives (Fernandez, 1997). It has been found that dowry-related aggression carried out by the mother-in-law and the husband correlate highly with each other (Khan et al., 2020).

In India, violence inflicted by mothers-in-law on their daughters-in-law is tried under the family law or dowry-related laws, and not as cases of gender-based violence. Moreover, the law generally is dominated by patriarchal views which overshadow the understanding of the abuse by mothers-in-law as a cause for legal action (Gangoli \& Rew, 2011).

Domestic aggression perpetrated by the mother-in-law towards the daughter-in-law is dependent on the stage of the life cycle in which the respective women of the house are in (Fernandez, 1997). It has been found that as the daughter-in-law grows older, the controlling behaviours perpetrated by the mother-inlaw diminish (Khan et al., 2021). Abused daughters-in-law of today most likely become batterers as mothers-in-law of tomorrow, thinking that it is finally their time to exert power (Fernandez, 1997).

\section{Objectives of the Study}

The aim of the study was to investigate victimisation of Pakistani married women from domestic aggression perpetrated by their mothers-in-law, and its psychological concomitants. The focus of previous research conducted on the South Asian joint family system has usually been on spousal abuse and the relationship between the husband and the wife, and there is very limited research on the role of mothers-in-law (Mirza, 2017). 


\section{Methodology}

\subsection{Subjects}

A questionnaire was completed by 569 women in Pakistan. The mean age was 31.4 years (SD 9.1), and the age range was between 18 and 70 years. Respondents were a convenience sample of relatively well-educated women from three cities in Pakistan: the capital Islamabad, and the two provincial capitals Lahore and Karachi.

\subsection{Instrument}

A questionnaire was constructed in order to investigate female victimisation from domestic aggression perpetrated by the mother-in-law, and its psychological concomitants. The following types of aggressive behaviours perpetrated by the mother-in-law against the daughter-in-law were measured: physical aggression, verbal aggression, and indirect aggressive social manipulation.

Physical and verbal aggression, and aggressive indirect social manipulation were measured with the Direct Indirect Aggression Scale for Adults (Österman \& Björkqvist, 2009). Items specifically suited for Pakistan were added (see below). All items of the scales started with the question: "How often has your mother-in-law done the following?". Single items and Cronbach's alphas for the scales are presented below. Items with an asterisk were not from the original scales but were added to them.

The scale measuring physical aggression included 13 items $(\alpha=.95)$ : "My mother-in-law has ...": hit me, locked me in, locked me out, shoved me, spit at me, thrown objects in anger, damaged something that was mine, kicked me*, tripped me when I was passing by*, pushed me back in order to prevent me from standing in front of her in different situations*, pulled my hair*, twisted my arm*, and intentionally burnt me with a cigarette*.

The scale measuring verbal aggression included 8 items $(\alpha=. .96)$ : "My mother-in-law has ..." yelled at me, quarreled with me, purposely said nasty or hurting things to me about my appearance, called me bad names, interrupted me when I was talking, angrily nagged at me, criticised my family and friends*, and teased me*.

The scale measuring aggressive indirect social manipulation included 12 items $(\alpha=.97)$ : "My mother-in-law has ..." spoken badly about me to someone else, tried to influence someone, such as children, relatives, or servants, to dislike me, ridiculed me in my absence, tried to exclude me from social situations, tried to make me feel guilty, made socially fun of my intellect*, made negative comparisons between me and her own daughters, nieces, or sisters*, regarded me as being lower than her family*, used social media and tagged in humiliating quotes and pictures of me*, gossiped to others about my family and upbringing*, plotted revenge against me in my absence*, and told false stories about me*.

Responses were given on a five-point scale $(0=$ never, $1=$ seldom, $2=$ sometimes, $3=$ often, 4 $=$ very often).

The psychological status of the daughter-in-law was measured with four standardised scales, anxiety, depression, obsessive compulsive symptoms, and somatisation, from the Brief Symptom Inventory (Derogatis \& Melisaratos, 1983). Responses were given on a five-point scale $(0=$ not at all, $1=$ a little, $2=$ moderately, $3=$ much, $4=$ very much $)$. The Cronbach's alphas of the scales were as follows: anxiety ( 6 items, $\alpha=.91$ ), depression ( 6 items, $\alpha=.92$ ), obsessive compulsive symptoms ( 5 items, $\alpha=.88$ ), and somatisation ( 8 items, $\alpha=.92$ ). 
In order to compare the levels of aggression perpetrated by the mothers-in-law with aggression perpetrated by the husbands, data from a previous study based on the same sample was used (Khan, Österman, Björkqvist, 2019). That study presented findings regarding intimate partner aggression perpetrated against the same women as in the present sample.

\subsection{Procedure}

The data were collected with an online questionnaire during a period of two and a half months in 2017. Respondents were a convenience sample of women from three cities in Pakistan: the capital Islamabad, and the two provincial capitals Lahore and Karachi.

\subsection{Ethical Considerations}

The study adheres to the principles concerning human research ethics of the Declaration of Helsinki (World Medical Association, 2013), guidelines for the responsible conduct of research of the Finnish Advisory Board on Research Integrity (2012), and the general data protection regulation of the European Union (European Commission, 2016).

\section{Results}

4.1 Three Types of Aggression Perpetrated by the Mothers-in-law against their Daughters-inlaw

The least common form of aggression that the mothers-in-law perpetrated against their daughters-in-law was physical aggression $(m=0.15)$. Verbal aggression $(m=0.66)$ and indirect aggression $(m=0.62)$ were significantly more common $\left[F_{(2,567)}=117.26, p<.001, \eta_{p}{ }^{2}=.293\right]$.

\subsection{Correlations between Victimisation from Three Types of Aggression and Psychological Concomitants}

All three types of aggression perpetrated by the mothers-in-law correlated significantly at a $p$ $<.001$-level with anxiety, depression, obsessive compulsive symptoms, and somatisation of the daughters-in-law (Table 1). In order to compare the correlational coefficients between the three types of victimisation and the four psychological concomitants, Fisher's $r$ to $z$ transformation was used: $\mathrm{z}=-\left(z_{r 1}-z_{r 2}\right) / \sqrt{(1 /(n 1-3)+1 /(n 2-3))}$ in which $z_{r}=1 / 2 \ln ((1+r) /(1-r))$. A $z$-value $\geq 1.96$ indicates $p<.05$. It was found that the correlational coefficients between anxiety, depression, obsessive compulsive symptoms, and somatisation with victimisation from physical aggression perpetrated by the mother-in-law were all significantly lower than the coefficients for victimisation from verbal and indirect aggression (Table 1).

Table 1. Correlations between Victimisation of Daughters-in-Law from Aggression Perpetrated by the Mother-in-Law and Four Psychological Concomitants $(N=569)$

\begin{tabular}{|c|c|c|c|c|}
\hline \multirow{3}{*}{$\begin{array}{l}\text { Psychological } \\
\text { Concomitants of the } \\
\text { Daughter-in-Law }\end{array}$} & \multicolumn{3}{|c|}{$\begin{array}{c}\text { Victimisation from Aggression } \\
\text { Perpetrated by the Mother-in-Law }\end{array}$} & \multirow{3}{*}{$\begin{array}{l}\text { Significant } \\
\text { differences } \\
\text { between } r \text { : }\end{array}$} \\
\hline & Physical & Verbal & Indirect & \\
\hline & $\mathrm{A}$ & $\mathrm{B}$ & $\mathrm{C}$ & \\
\hline Anxiety & $.36 * * *$ & $.58 * * *$ & $.63 * * *$ & $\mathrm{~A}<\mathrm{B}, \mathrm{C}$ \\
\hline Depression & $.32 * * *$ & $.55 * * *$ & $.62 * * *$ & $\mathrm{~A}<\mathrm{B}, \mathrm{C}$ \\
\hline Obsessive Compulsive Symptoms & $.25 * * *$ & $.52 * * *$ & $.58 * * *$ & $\mathrm{~A}<\mathrm{B}, \mathrm{C}$ \\
\hline Somatisation & $.37 * * *$ & $.55 * * *$ & $.61 * * *$ & $\mathrm{~A}<\mathrm{B}, \mathrm{C}$ \\
\hline
\end{tabular}




\subsection{Comparison between Victimisation from Aggression Perpetrated by the Mothers-in-law and the Husbands}

A within-subjects multivariate analysis of variance (WSMANOVA) was conducted in order to compare the frequencies of victimisation from three types of aggression (physical, verbal, and indirect) perpetrated by the mothers-in-law and by the husbands respectively (Fig. 1.). The multivariate analysis was significant $\left[F_{(3,566)}=70.64, p<.001, \eta_{p}{ }^{2}=.272\right]$. The univariate analyses showed that the husbands perpetrated physial aggression against their wife significantly more often than the mother-in-laws against their daughters in law $\left[F_{(1,568)}=14.08\right.$, $\left.p<.001, \eta_{p}{ }^{2}=.024\right]$. The husbands also perpetrated significantly more verbal aggression than the mothers-in-law $\left[F_{(1,568)}=46.42, p<.001, \eta_{p}^{2}=.076\right]$. However, the mothers-in-law perpetrated significantly more indirect aggression against the daughters-in-law than the husbands $\left[F_{(1,568)}=33.01, p<.001, \eta_{p}^{2}=.055\right]$.

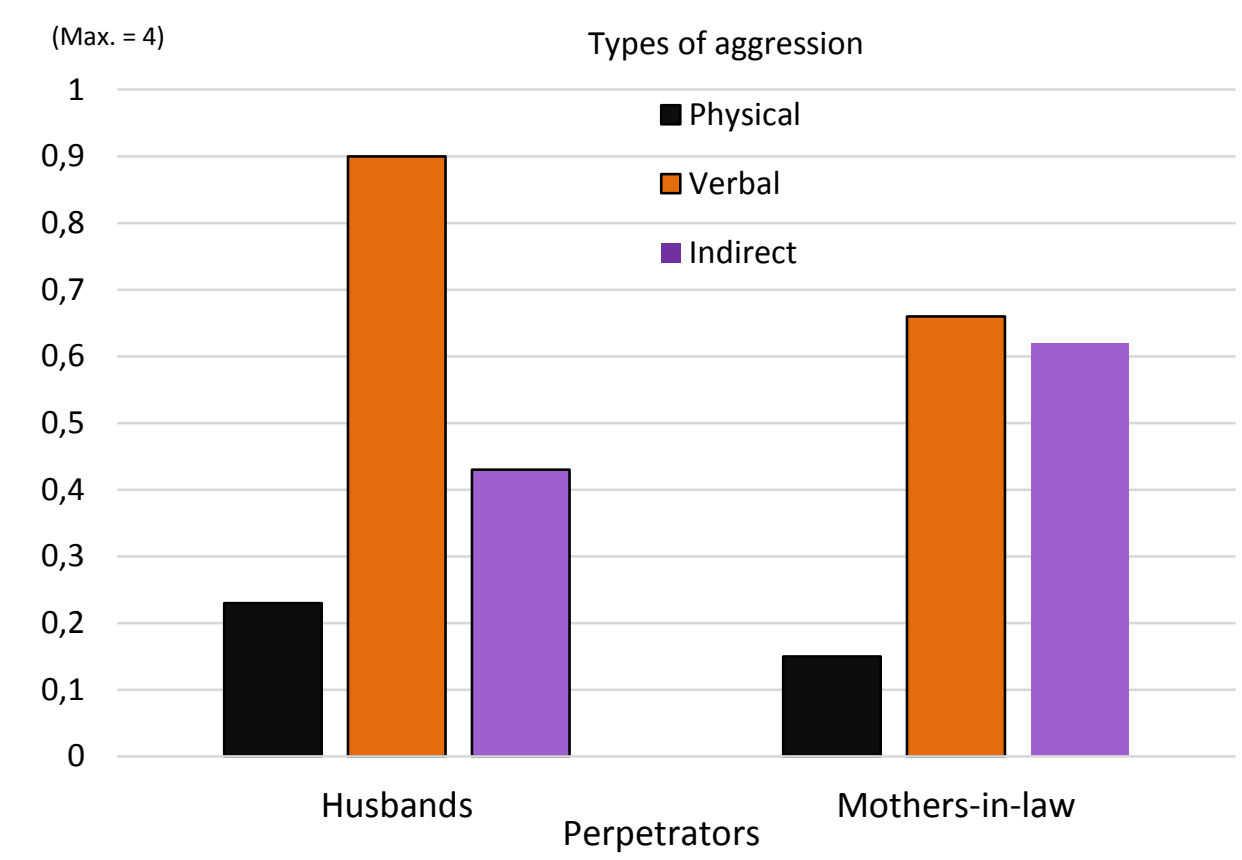

Fig. 1. Mean values on victimisation of the wives from three types of aggression perpetrated by the husbands and by the mothers-in-law $(N=569)$.

\section{Discussion}

\subsection{The Preferred Styles of Aggression Among the Mothers-in-Law}

Research on mothers-in-law in South Asian extended families has until now been scarce, especially about the types of aggressive encounters that may occur between mothers-in-law and daughters-in-law. In the present study, it was found that the least common form of aggression that the mothers-in-law perpetrated against their daughters-in-law was physical aggression. Verbal aggression and indirect aggression were significantly more common. This finding is in line with previous studies on female aggression. When three types of aggressive behaviours, physical, verbal, and indirect, of adolescents in Finland, Israel, Italy, and Poland were studied, it was found that indirect aggression was, in proportional terms, the aggressive style most used by girls, across nations, ethnic groups, and age groups studied (Österman, Björkqvist, 
Lagerspetz, Kaukiainen, Landau, Fraczek, \& Caprara, 1998). Verbal aggression was the second most used style by girls, and physical aggression was used least often by girls. The present study follows a similar pattern in terms of sex differences.

It has been argued that females tend to avoid physical aggression in order not to expose themselves to physical danger. Björkqvist (1994) suggested that sex differences regarding aggressive behaviour may be theoretically explained by what he referred to as the effect/danger (cost/benefit) ratio. This ratio is an expression of the subjective estimation of the likely consequences of an aggressive act. The aggressor, consciously or unconsciously, assesses the relation between the intended aggressive strategy and the danger involved, being either physical or psychological. The objective is to find a technique that is as effective as possible and at the same incurs as little danger as possible: to maximize effect and minimize risk. Since girls and women are physically weaker than boys and men, they already early in life learn that physical aggression does not pay for them, and instead, they learn to rely on verbal, and especially indirect means of aggression, which expose them to little direct danger (Björkqvist, 1994). In the current study, it was shown that the female preference for indirect means of aggressive behaviour can be observed also among mothers-in-law in the extended family context. The present study is the first to report this fact.

\subsection{Psychological Concomitants of the Aggression Perpetrated by the Mothers-in-law}

Symptoms of anxiety, depression, obsessive compulsion, and somatisation of the daughters-inlaw were all clearly associated with aggression perpetrated by the mothers-in-law. This finding suggests that there are serious mental health concomitants associated with the aggressive behaviour from the part of the mothers-in-law. Since the study design was cross-sectional, not longitudinal, it is not possible to make inferences about cause and effect, but it appears likely that the victimisation of the daughters-in-law may indeed be an effect of the negative behaviour they have been exposed to. Victimisation from domestic aggression in Pakistan has previously been found to be associated with psychological problems of the victims (Khan, Österman, \& Björkqvist, 2019; Khan et al., 2020).

In the study, it was found that the association between anxiety, depression, obsessive compulsive symptoms, and somatisation with victimisation from physical aggression perpetrated by the mothers-in-law were all weaker than the association with victimisation from verbal and indirect aggression. The reason for this circumstance might be the fact that the mothers-in-law used physical aggression more seldom than the other two types of aggression, and accordingly, since the daughters-in-law were exposed to verbal and indirect aggression more often, it also left deeper scars.

\subsection{Aggression Perpetrated by the Mothers-in-law in Comparison with Aggression by the Husbands}

In the study, the husbands perpetrated physical aggression against their wives significantly more often than the mother-in-laws against their daughters in law. This appears logical, since, as mentioned above, physical aggression is known to be perpetrated more often by males than by females.

The husbands also perpetrated significantly more verbal aggression than the mothers-in-law. However, the mothers-in-law perpetrated significantly more indirect aggression against the daughters-in-law than the husbands against their wives. This finding is also in line with what is previously known about sex differences in aggression (Björkqvist, 1994; 2018). 
The symptoms of psychological distress associated with the aggression perpetrated by the mothers-in-law were in magnitude quite comparable to the symptoms associated with aggression perpetrated by the husbands, which have been reported elsewhere (Khan et al., 2020).

\subsection{Limitations and Suggestions for Further Research}

The primary difficulty of the study was to reach out to the women, to prove to them the confidentiality and the anonymity of the study and request them to respond honestly. Marriages are considered to be extremely sacred in South Asia, and hence, the respondents could not take any risk of putting their marital lives at risk. However, with the help of interventions by some NGOs and a government run female welfare and protection center, women could be made to feel more confident to participate in the study.

One limitation of the study is that the sample cannot be claimed to be representative for the whole population. Only women belonging to the well-educated and high-income group of society were represented in the sample. Respondents belonged to only the top three urban centers of Pakistan: Lahore, Karachi, and Islamabad. A wider perspective on the issue could be brought forward through reaching out to women belonging to all socio-economic classes and areas of the country.

\subsection{Conclusions}

The study explored one of the oldest, psychologically scarring, deep-rooted, and yet, rarely highlighted issue of marital lives of daughters-in-law and mothers-in-law living in South Asia. Further studies can open up avenues to bring down many centuries of old traditions of oppression of women and enlightening them about their rights and what they are actually worthy of.

\section{References}

[1] Ali, P., A., O'Cathain, A., \& Croot, E. (2018). Influences of extended family on intimate partner violence: Perceptions of Pakistanis in Pakistan and the United Kingdom. Journal of Interpersonal Violence, 129. doi:10.1177/0886260518785378.

[2] Björkqvist, K. (1994). Sex differences in physical, verbal, and indirect aggression: A review of recent research. Sex Roles, 30, 177-188.

[3] Björkqvist, K. (2018). Gender differences in aggression. Current Opinion in Psychology, 19, 30-42. doi:10.1016/j.copsyc.2017.03.030

[4] Char, A., Saavala, M., \& Kulmala, T. (2010) Influence of mothers-in-law on young couples' family planning decisions in rural India. Reproductive Health Matters, 18, 154-162. doi:10.1016/ S0968-8080(10)35497-8

[5] Derogatis, L. R., \& Melisaratos, N. (1983). The Brief Symptom Inventory: Introductory Report. Psychological Medicine, 13, 595-605

[6] European Commission (2016). Data protection. Rules for the protection of personal data inside and outside the EU. https://ec.europa.eu/info/law/law-topic/dataprotection_en

[7] Fernandez, M. (1997). Domestic violence by extended family members in India: Interplay of gender and generation. Journal of Interpersonal Violence, 12, 433-455. doi:10.1177/088626097012003008 
[8] Finnish Advisory Board on Research Integrity (2012). Responsible conduct of research and procedures for handling allegations of misconduct in Finland. Helsinki: Finnish Advisory Board on Research Integrity.

[9] Gangoli, G., \& Rew, M. J. (2011). Mothers-in-law against daughters-in-law: Domestic violence and legal discourses around mother-in-law violence against daughters-in-law in India. Women's Studies International Forum 34, 420-429.

[10] Khan, T., Österman, K., \& Björkqvist, K. (2019). Victimization from three types of intimate partner aggression and mental health concomitants among women in Pakistan. Journal of Educational, Health and Community Psychology, 8, 3, E-ISSN 2460-8467.

[11] Khan, T., Österman, K., \& Björkqvist, K. (2020). Dowry-related aggression and mental health concomitants among educated women in Pakistan. Journal of Educational, Health, and Community Psychology, 9, 442-457.

[12] Khan, T., Österman, K., \& Björkqvist, K. (2021). Mental health concomitants related to controlling behaviours perpetrated by husbands and mothers-in-law in Pakistan. Technium Social Science Journal, 16, 302-313.

[13] Kumar, A., Burdone, V., \& Muttarak, R. (2016). Like mother(-in-law) like daughter? Influence of the older generation's fertility behaviours on women's desired family size in Bihar, India. European Journal of Population, 32, 629-660.

[14] Mahmood, N. (2002). Women's role in domestic decision-making in Pakistan: Implications for reproductive behaviour. The Pakistan Development Review, 41, 121148.

[15] Mies, M. (1980). Indian women and patriarchy. New Delhi, India: Concept.

[16] Mirza, N. (2017). South Asian women's experiences of family abuse: The role of the husband's mother. School of Social and Political Science, PhD Thesis, University of Glasgow, Scotland.

[17] Österman, K., \& Björkqvist, K. (2009). Direct Indirect Aggression Scales for Adults (DIAS-Adult). Åbo Akademi University, Finland

[18] Österman, K., Björkqvist, K., Lagerspetz, K. M. J., with Kaukiainen, A., Landau, S. F., Fraczek, \& Caprara, G. V. (1998). Cross-cultural evidence of female indirect aggression. Aggressive Behavior, 24, 1-8.

[19] Rew, M., Gangoli, G., \& Gill, A., K. (2013). Violence between female in-laws in India. Journal of International Women's Studies 14, 147-160.

[20] Simkhada, B., Porter, M. A., \& van Teijlingen, E. R. (2010). The role of mothers-inlaw in antenatal care decision-making in Nepal: a qualitative study. BMC Pregnancy and Childbirth, 10, 34.

[21] Wasim, F. (2014). South Asian American daughter-in-law/ mother-in-law relationships, cultural values conflict, and help-seeking for domestic violence. $\mathrm{PhD}$ Thesis, Kennesaw State University, Georgia, USA.

[22] World Medical Association (2013). World Medical Association Declaration of Helsinki. Ethical principles for medical research involving human subjects. Bulletin of the World Health Organization, 79, 373-374. 